\title{
Macular Pigmentation Following Low Fluence Nd:YAG Laser Procedure at Sites of Gold Thread Implantation
}

\author{
Dae Young Oh, Kyung Eun Jung, Joong Sun Lee, Dae Won Koo \\ Department of Dermatology, Eulji University Hospital, Eulji University School of Medicine, Daejeon, Korea
}

\begin{abstract}
Use of gold thread rejuvenation and Q-switched low fluence neodymium-doped yttrium aluminum garnet (Nd:YAG) laser treatments have become a recent fashion trend in the skin care industry, and are frequently used for skin care management. Although the efficacy and side effects of the individual procedures have been well documented, the combined effects of the two treatments have not been reported. We describe a unique case of macular pigmentation on the face, resulting from the low fluence $\left(3 \mathrm{~J} / \mathrm{cm}^{2}\right) \mathrm{Nd}$ :YAG laser procedure solely at the sites of gold thread implantation. A skin biopsy revealed rod-shaped foreign material and tiny golden colored granules surrounded by minor inflammatory infiltrates. Therefore, the use of a Nd:YAG laser at a specific wavelength (potentially $1064 \mathrm{~nm}$ ) may trigger macular pigmentation when in contact with pre-implanted gold threads by as yet unknown mechanism. (Ann Dermatol 31(1) $78 \sim$
\end{abstract} 80, 2019)

\section{-Keywords-}

Gold, Neodymium-doped yttrium aluminum garnet laser, Rejuvenation

Received September 25, 2017, Revised January 2, 2018, Accepted for publication February 5, 2018

Corresponding author: Dae Won Koo, Department of Dermatology, Eulji University Hospital, Eulji University School of Medicine, 95 Dunsanseo-ro, Seo-gu, Daejeon 35233, Korea. Tel: 82-42-611-3035, Fax: 82-42-259-1111, E-mail: dwkoo@eulji.ac.kr

ORCID: https://orcid.org/0000-0001-8587-0205

This is an Open Access article distributed under the terms of the Creative Commons Attribution Non-Commercial License (http://creativecommons. org/licenses/by-nc/4.0) which permits unrestricted non-commercial use, distribution, and reproduction in any medium, provided the original work is properly cited.

Copyright (c) The Korean Dermatological Association and The Korean Society for Investigative Dermatology

\section{INTRODUCTION}

Given the stability of gold and the ease of the procedure, gold thread rejuvenation therapy is often performed for skin care treatments such as skin rejuvenation. Importantly, gold therapy has been reported an effective treatment for the improvement of the appearance of the aging skin such as the elimination or reduction of facial wrinkles and improvement of skin elasticity. However, despite its noted efficacy, many side effects have been reported as well ${ }^{1}$. Here, we describe a case of macular pigmentation caused by using low fluence neodymium-doped yttrium aluminum garnet (Nd:YAG) laser (1064 nm) after gold thread implantation was performed for facial rejuvenation.

\section{CASE REPORT}

A 47-year-old female patient presented with asymptomatic brownish macules on her left cheek, which had persisted for one year. She had a history of gold thread insertion performed for a facial skin lift at these sites six years ago. In addition, low fluence (3 J/cm ${ }^{2}$ ) Nd:YAG (1064 nm) laser procedures were performed three times for facial skin toning at a local clinic. She felt some transient burning sensation shortly after the laser procedures and soon discovered pigmentation on the face. The number and size of the lesions remained almost constant afterwards. Physical examination revealed multiple, unilaterally distributed, well-demarcated round-shaped, firm, varying degrees of brownish macules on the left cheek (Fig. 1A, B).

Histopathological examination of the cheek revealed golden-brownish rod-shaped foreign material and some fine golden granules in the deep dermis $(1.4 \mathrm{~mm})$ that was suspected to be gold. There was little inflammatory reaction around the substance, although there was some fibrosis and collagen bundle enlargement. Additionally, there was 

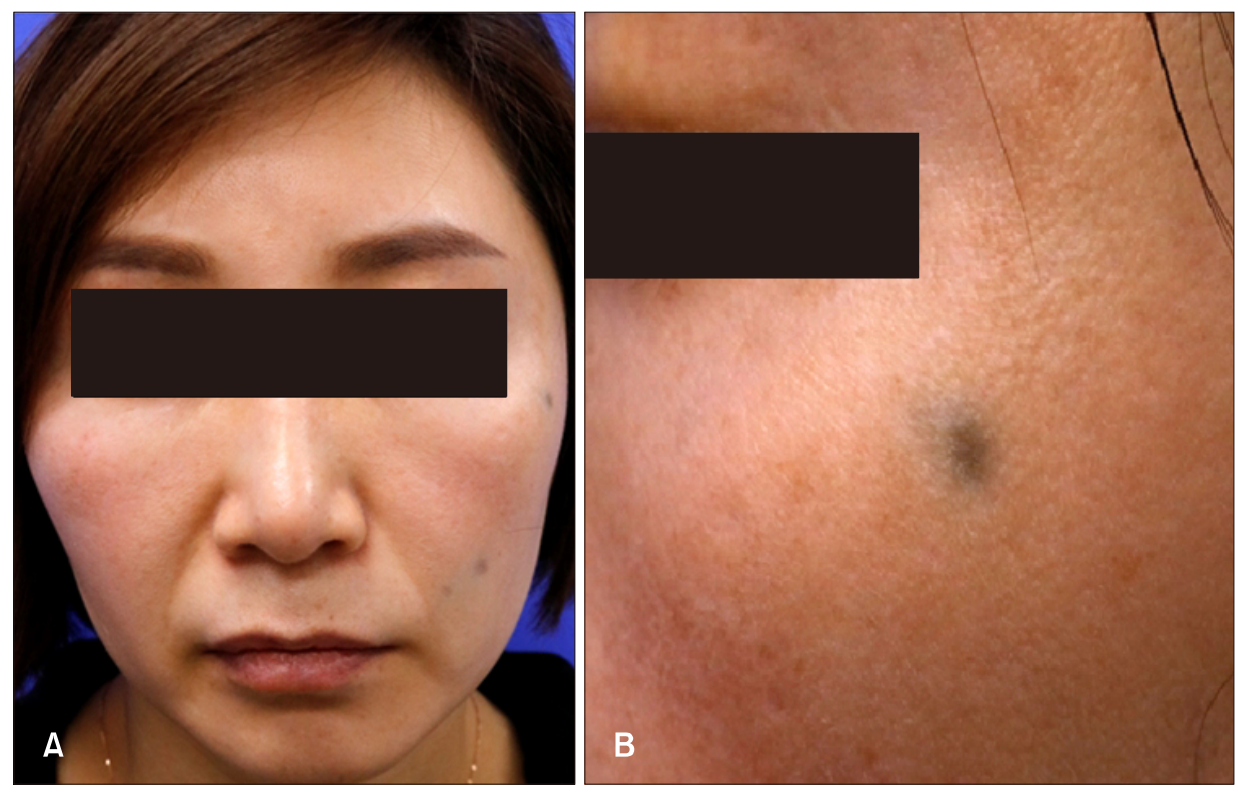

Fig. 1. (A) Brownish macules unilaterally distributed on the left side of the face. (B) Close-up view of well-demarcated, round-shaped, pigmented macules on the left cheek.
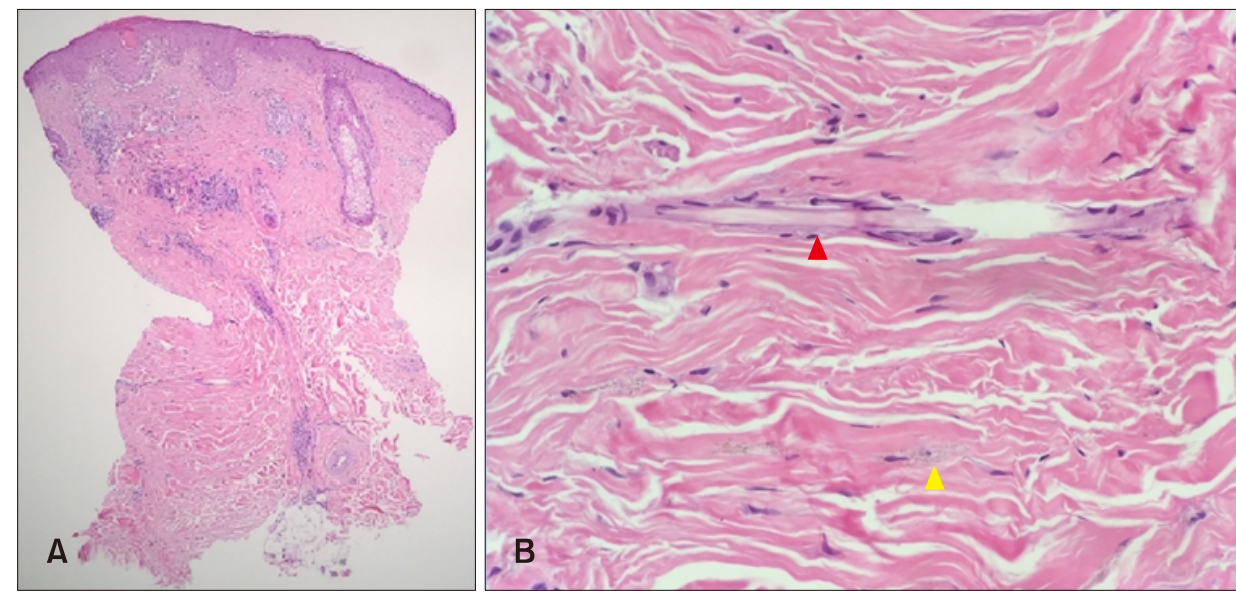

Fig. 2. (A) Histopathologic findings show mild fibrosis and minor inflammatory infiltrates in the upper dermis $(\mathrm{H} \& \mathrm{E}, \times 40)$. (B) At higher power, rod-shaped foreign material (red arrowhead) and fine golden colored granules (yellow arrowhead) in the deep dermis $(1.4 \mathrm{~mm})(\mathrm{H \& E}, \times 400)$. no evidence of granuloma (Fig. 2A, B).

\section{DISCUSSION}

Gold has long been regarded as a safe and stable metal when in contact with skin and mucosal membranes ${ }^{2}$. Therefore, due to these non-allergic, non-infective, chemically stable characteristics, it has been widely used as dental filling material, as accessories which directly attach to the skin, and various other medical uses, including cardiac coronary artery stents. Since the first gold thread implantation was performed by Dr. Caux in France, with subsequent histologic changes in the skin confirmed by Adamyan and colleagues, gold thread rejuvenation has been frequently used for improving skin structure and appearance ${ }^{3}$. Furthermore, gold particles inserted into the dermis can stimulate collagen growth and angiogenesis of the surrounding area ${ }^{1,4}$.

In this case study, the Nd:YAG laser was initially thought to be the causal factor for the macular pigmentation given the seemingly immediate occurrence following the procedure. Although the Nd:YAG laser can cause post-inflammatory hyperpigmentation, no pigmentary incontinence or severe dermal inflammation was observed when the patient's biopsy was examined histologically. In addition, these lesions only appeared at the sites of previous gold thread implantations, and not in areas where she had undergone whole laser treatment.

In the six years after the gold thread insertion procedure and the appearance of the hyperpigmentation, there was no presence of any granuloma or severe inflammation in the dermis as seen by histology. Considering these points, 
her symptoms may not have arose as a result of a latent foreign body reaction to the gold itself nor from allergic contact dermatitis to the gold ${ }^{2,4-6}$.

Therefore, we surmised that these lesions were not simply a response to the gold itself, but there may be a correlation between the laser's specific wavelength to the presence of the gold. Among the papers that have reported on the wavelength of the laser, Xing et al. ${ }^{7}$, concluded that the $1064 \mathrm{~nm} \mathrm{Nd:YAG} \mathrm{laser} \mathrm{could} \mathrm{change} \mathrm{the} \mathrm{shape} \mathrm{of}$ gold. Surface melting of gold and the morphologic changes from rod to sphere occurs when gold nano-rods encounter high laser energy density nanosecond $\mathrm{Nd}$ :YAG laser (6 $\left.14 \mathrm{~J} / \mathrm{cm}^{2}\right)$. As the frequency of laser radiation increases, the likelihood of change may increase. Given this phenomenon, it is conceivable that the repeated $\mathrm{Nd}$ :YAG laser procedures might change the surface or the shape of the pre-inserted gold coated polydioxanone thread, triggering pigmentary changes on the face. Here, the patient underwent three such laser procedures which multiple-passes technique is usually used for skin toning ${ }^{8}$. The fact that no further developments or changes were observed after laser therapy also reduced the possibility of other causes. In 2009, a case of paradoxical darkening of tattoo ink after low fluence $\left(2 \mathrm{~J} / \mathrm{cm}^{2}\right) 1064 \mathrm{~nm} \mathrm{Nd}$ :YAG was reported that the interaction of ferric oxide and the laser is presumed to be the causative for the of the darkening $^{8}$. It empowers our opinion that the interaction of the laser and the pre-inserted material in the skin is a key factor to the pigmentation. We note that further cases and in vivo experiments on the interaction between gold and the $\mathrm{Nd}$ :YAG laser are warranted to support this view.

Gold, which was considered relatively safe in the past, but has recently been reported to have side effects in the body such as allergic gold dermatitis and pseudolymphoma ${ }^{2,5,6}$. Allergic gold dermatitis may present as chronic eczematous papules, which have severe dermal involvement histologically ${ }^{2}$. Pseudolymphoma caused by gold, which is not uncommon in Asian countries may exhibit a benign course with microscopic appearance that resembles cutaneous lymphoma ${ }^{5}$. However, to our knowledge, this is the first case of skin lesions presenting as brownish macular eruptions caused by the addition of $\mathrm{Nd}$ :YAG laser procedures following gold thread insertion.

Recently, gold thread rejuvenation and laser therapy have been performed frequently to meet the demands of the growing interest in cosmetic therapies and the skin industry. Although gold or laser treatments alone may have minor known side effects, physicians should be aware of the possibility of interactions that may occur with gold and Nd:YAG laser that can lead to irreversible skin damage as well as potentially irreversible sequelae.

\section{ACKNOWLEDGMENT}

We received the patient's consent form about publishing all photographic materials.

\section{CONFLICTS OF INTEREST}

The authors have nothing to disclose.

\section{ORCID}

Dae Young Oh, https://orcid.org/0000-0001-6084-7893

Kyung Eun Jung, https://orcid.org/0000-0003-0968-1079

Joong Sun Lee, https://orcid.org/0000-0003-2562-4090

Dae Won Koo, https://orcid.org/0000-0001-8587-0205

\section{REFERENCES}

1. Shin KC, Bae TH, Kim WS, Kim HK. Usefulness of gold thread implantation for crow's feet. Arch Plast Surg 2012; 39:42-45.

2. Armstrong DK, Walsh MY, Dawson JF. Granulomatous contact dermatitis due to gold earrings. Br J Dermatol 1997; 136:776-778.

3. Rondo Júnior W, Vidarte G, Michalany N. Histologic study of the skin with gold thread implantation. Plast Reconstr Surg 1996;97:256-258.

4. Moulonguet I, Arnaud E, Plantier F, da Costa P, Zaleski S. Histopathologic and ultrastructural features of gold thread implanted in the skin for facial rejuvenation. Am J Dermatopathol 2015;37:773-777.

5. Kim KJ, Lee MW, Choi JH, Sung KJ, Moon KC, Koh JK. CD30-positive T-cell-rich pseudolymphoma induced by gold acupuncture. Br J Dermatol 2002;146:882-884.

6. Seok J, Park KY, Li K, Kim BJ, Seo SJ, Kim MN, et al. Multiple papular eruptions at insertion site of gold-coated polydioxanone thread. Dermatol ther 2017;30:e12416.

7. Xing L, Chen B, Li D, Ma J, Wu W, Wang G. Nd:YAG laser-induced morphology change and photothermal conversion of gold nanorods with potential application in the treatment of port-wine stain. Lasers Med Sci 2017;32: 629-640.

8. Chung WK, Yang JH, Lee DW, Chang SE, Lee MW, Choi $\mathrm{JH}$, et al. Paradoxical darkening of unperceived tattoo ink after relatively low fluence from a Q-switched Nd:YAG (1064-nm) laser in the course of treatment for melasma. Clin Exp Dermatol 2009;34:e555-557. 